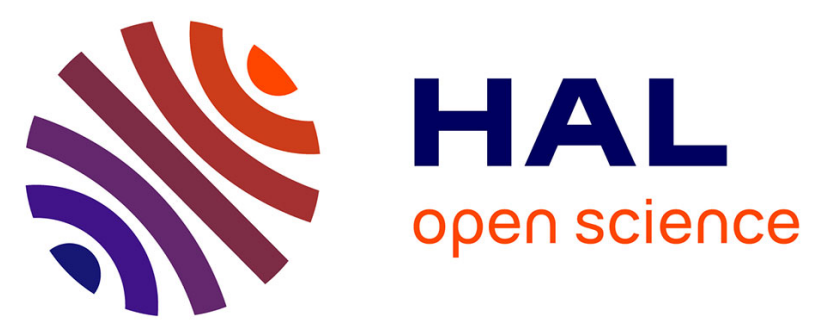

\title{
Free induction decay signals stimulated by photomixing
}

Fuanki Bavedila, Guillaume Ducournau, Jean-Francois Lampin, Emilien

Peytavit, A. Cuisset, Gaël Mouret, Cyril Bray, Robin Bocquet, F. Hindle

\section{To cite this version:}

Fuanki Bavedila, Guillaume Ducournau, Jean-Francois Lampin, Emilien Peytavit, A. Cuisset, et al.. Free induction decay signals stimulated by photomixing. IRMMW-THz 2019 44th International Conference on Infrared, Millimeter, and Terahertz Waves, Sep 2019, Paris, France. 10.1109/IRMMWTHz.2019.8874516 . hal-02323479

\section{HAL Id: hal-02323479 https://hal.science/hal-02323479}

Submitted on 21 Oct 2019

HAL is a multi-disciplinary open access archive for the deposit and dissemination of scientific research documents, whether they are published or not. The documents may come from teaching and research institutions in France or abroad, or from public or private research centers.
L'archive ouverte pluridisciplinaire HAL, est destinée au dépôt et à la diffusion de documents scientifiques de niveau recherche, publiés ou non, émanant des établissements d'enseignement et de recherche français ou étrangers, des laboratoires publics ou privés. 


\title{
Free Induction Decay signals stimulated by photomixing
}

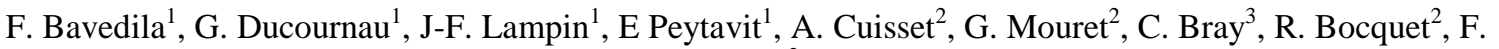 \\ Hindle $^{2}$ \\ ${ }^{1}$ IEMN, UMR CNRS 8520, Université de Lille, 59652, Villeneuve d'Ascq, France \\ ${ }^{2}$ Laboratoire de Physico-Chimie de l'Atmosphère, ULCO, Dunkerque 59140, France \\ ${ }^{3}$ Univ. Bordeaux, Institut des Sciences Moléculaires, UMR 5255, F-33400 Talence, France
}

\begin{abstract}
An optically driven photoconductor device is electrically pulsed to provide a powerful pulse around $206 \mathrm{GHz}$. The pulsed radiation polarizes the OCS gas which emits a free induction decay signal that is observed after the end of the pulse. This is the first step in the development of a photonic chirped pulsed spectrometer.
\end{abstract}

$\mathrm{E}$ LECTRONIC sources have been allowed the development of Chirped Pulsed spectrometers which are now a competitive alternative for high-resolution spectroscopy of gases in the $\mathrm{mm}$ and sub-mm regions[1], [2]. Such instruments operate by polarizing the gas with a powerful pulse of radiation. After the extinction of the pulse a sensitive detection scheme is used to record the Free Induction Decay (FID) signal. The performance of modern high-speed electronics such as Arbitrary Waveform Generators (AWG) and fast real-time oscilloscopes have been key to this development. Repeatable phase identical pulses allow a particularly efficient accumulation over a large number of measurement cycles. The principal shortcoming occurs when access is required to a large range of frequencies. In the sub$\mathrm{mm}$ range a single frequency multiplication emitter or mixer is typically limited to a bandwidth generally not exceeding +/$20 \%$ of the central frequency. A large number of expensive components are required if a wide band coverage for comprehensive analysis is desired. Optically driven photoconductor devices, also called photomixer, have already demonstrated their use as emitters or receivers, a single device having the capacity to operate from $100 \mathrm{GHz}$ to at least $1 \mathrm{THz}$.

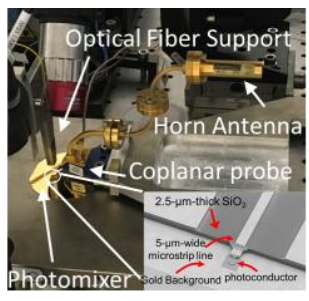

TX Optoelectronics

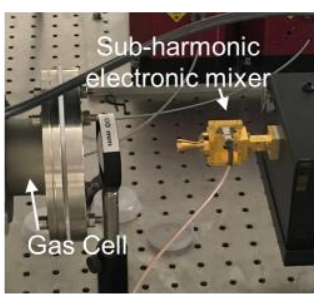

$\mathrm{RX}$ Electronics
Fig. 1. Experimental Set-up of the Optoelectronics Free induction Decay experiment

Here we have demonstrated the generation of FID signals using a photomixer, consisting in a low-temperature-grown (LTG) GaAs Fabry-Pérot cavity photoconductor[3], [4]. A series of pulses are formed by applying a corresponding pulse waveform to the photoconductor bias. The device is illuminated by two lasers which are detuned around the frequency of the OCS transition at $206.745 \mathrm{GHz}$. The emission generation is coupled to a $140-220 \mathrm{GHz}$ waveguide coplanar probe, launched into free space by a horn antenna and propagated through a gas cell. The FID signal emitted by the gas is mixed with a local oscillator at $206 \mathrm{GHz}$ using a WR5.1 sub harmonic mixer (as shown on Fig. 1). The intermediate frequency signal was then amplified $(32 \mathrm{~dB})$ and recorded with a standard oscilloscope with a $2.5 \mathrm{GHz}$ bandwidth. Typical signals are given in figure 1 for OCS as a function of pressure. The amplitude of the pulse decreases with the increased molecular absorption at higher pressure. The FID signal is observed after the pulse has finished, at 19 $\mu$ bars the signal is weak while at $66 \mu$ bars the signal is stronger but has a longer decay time compared to the signal for $227 \mu$ bars. At the present time no further signal accumulation can be performed as there is no relation between the phase of the emission pulse and the local oscillator. To unlock the high degree of accumulation typically employed by chirped pulsed spectrometers the same beating frequency used for the generation should also be used for the detection process. For this reason, a Mach-Zehnder modulator has been inserted into the setup, in this case the molecular line can be probed by one of the sidebands while, the carrier is available for detection. The first proof of concept measurements have also been performed using the modulator.

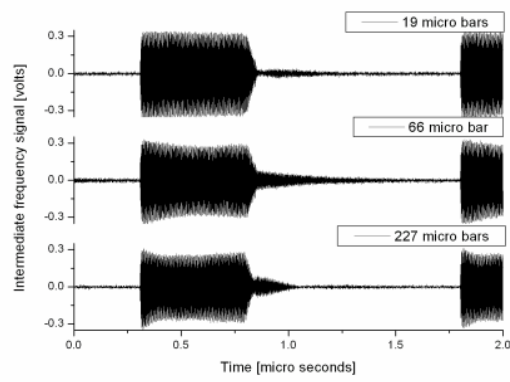

Fig. 2. Signal recorded during after and after the THz pulses for three different pressures of OCS. The FID signal can be observed after the extinction of the pulse at approximately $0.8 \mu \mathrm{s}$.

\section{REFERENCES}

[1]
A. L. Steber, B. J. Harris, and J. L. Neill, “An arbitrary waveform generator based chirped pulse Fourier transform spectrometer operating from 260 to $295 \mathrm{GHz}$," J. Mol. Spectrosc., vol. 280, pp. 3-10, Oct. 2012

F. Hindle et al., "Chirped Pulse Spectrometer Operating at 200 GHz," J. Infrared, Millimeter, Terahertz Waves, vol. 39, no. 1, pp. 105-119, Jan. 2018.

E. Peytavit, P. Latzel, F. Pavanello, G. Ducournau, and J.-F. Lampin, "CW Source Based on Photomixing With Output Power Reaching $1.8 \mathrm{~mW}$ at $250 \mathrm{GHz}$," IEEE Electron Device Lett., vol. 34, no. 10, pp. 1277-1279, Oct. 2013. 
[4] E. Peytavit et al., "Milliwatt-level output power in the sub-terahertz range generated by photomixing in a GaAs photoconductor," Appl. Phys. Lett., vol. 99, no. 22, p. 223508, 2011. 